\title{
ANALYSIS OF MINIMUM RAIL SIZE IN HEAVY AXLE LOAD ENVIRONMENT
}

\author{
David Y. Jeong \\ A. Benjamin Perlman \\ Volpe National Transportation Systems Center \\ Research and Innovative Technology Administration \\ US Department of Transportation \\ Cambridge, Massachusetts, USA
}

\section{ABSTRACT}

The effects of increasing axle loads on rail integrity are examined in this paper. In the present context, rail integrity refers to the prevention and control of rail failures. Rail failures usually occur because cracks or defects develop and grow from cyclic forces caused by the repeated passage of wheel loads over the rails, i.e. metal fatigue. Once a crack or defect has formed, it may grow to a critical size and cause a sudden fracture of the rail. Moreover, a broken rail may cause a train to derail.

Rail integrity evaluations are performed in this paper by applying a framework developed previously to estimate track capacity. The framework is exercised using two different criteria while varying axle loads: (1) allowable rail deflections and bending stresses, and (2) metal fatigue characterized in terms of propagation life (also referred to as slow crack-growth life). The engineering analyses based on these criteria are described. Results from these analyses are used to provide the rational basis for estimating the minimum rail size under heavy axle loads.

\section{INTRODUCTION}

Freight railroads in North America continually strive to increase their productivity by transporting greater amounts of goods each year. Consequently, average axle loads have steadily increased over time. During the 1970s, the railroads underwent a transition from cars with a nominal capacity of 70 tons (i.e., 27-ton axle load) to 100-ton cars (i.e., 33-ton axle loads). Based on recent trends, the nominal freight-car capacity is expected to reach 125 tons (i.e., 39-ton axle loads). This trend of steadily increasing nominal freight-car capacity over time is shown schematically in Figure 1. Such trends, however, raise concerns regarding increased track degradation rates due to heavier axle loads. Moreover, an assessment of the track conditions required to support heavier axle loads seems selfevident, and is the topic of this paper.

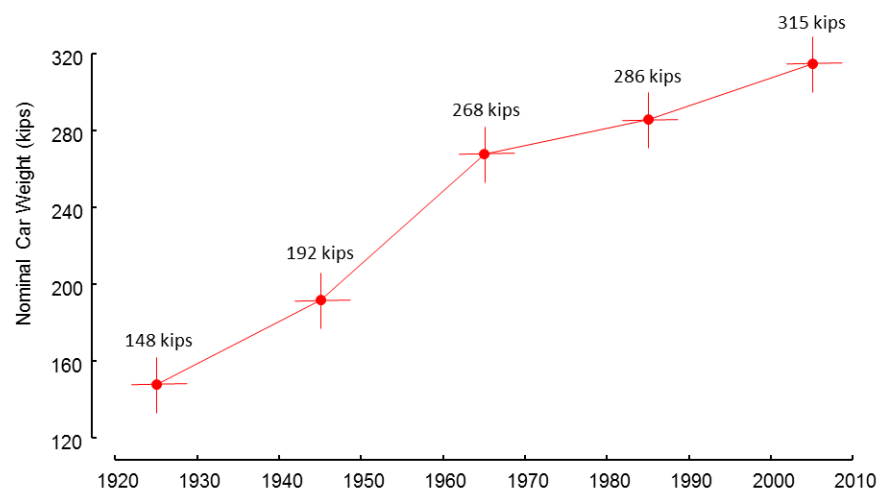

Figure 1: Evolution of Nominal Freight Car Capacity

According to statistics published by the Association of American Railroads [1], the Class 1 railroads in North America operated trains on over 112,000 miles of track in 2011. Figure 2 shows the weight of rail in place based on the 2011 track mileage statistics. This figure indicates that more than 32,000 miles, or $29 \%$ of all track operated by Class I railroads, comprise rail that is less than 130 pounds per yard. It is reasonable to assume that the percentage of lower weight rail would be higher if the track miles operated by the short line railroads, much of which consists of older and lighter rail, were also included in the total.

Rail failure is one of the leading causes of derailments in track. For example, Figure 3 shows data from the Federal Railroad Administration (FRA) Railroad Accident and Incident Reporting System (RAIRS) for track-caused incidents between 1975 and 2011 [2]. The track-caused incidents are divided into five categories: (1) rail and joints, (2) crosstie and gage, (3) geometry, (4) switches and turnouts, and (5) others. The figure indicates that broken rails and joints account for between $20 \%$ and $33 \%$ of the total track-caused incidents annually. 


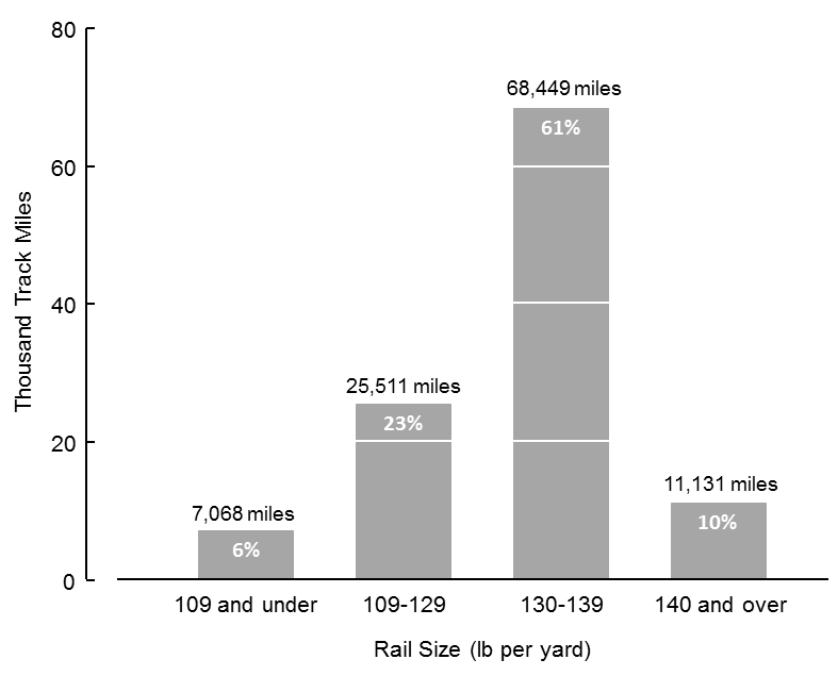

Figure 2: Weight of Rail in Place, 2011 [1]

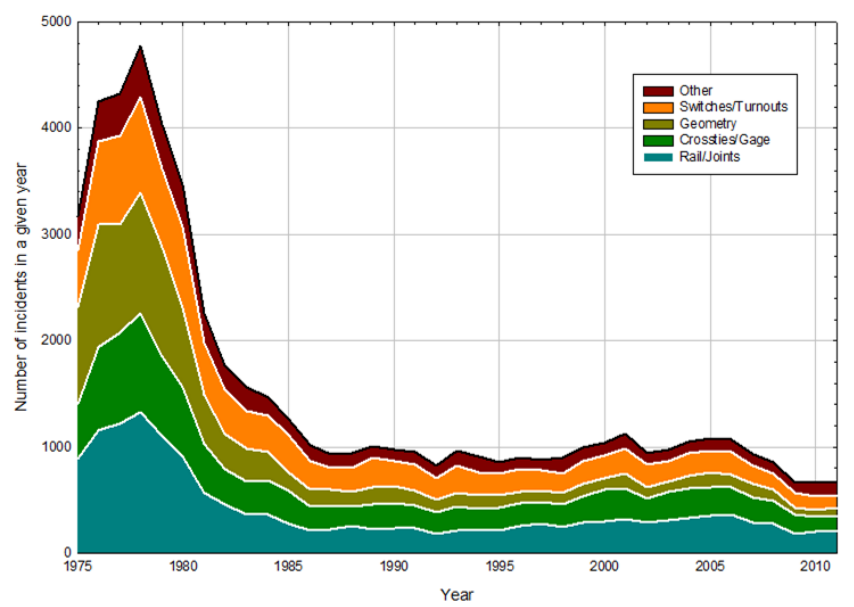

Figure 3: Track-caused Incidents from RAIRS [2]

The consequences from such accidents translate into safety and economic concerns for the industry and the Government regulatory agencies, such as the FRA and Transport Canada. Understanding the circumstances under which rail failure is likely to occur would be useful in determining effective strategies for rail testing, rail renewal, and maintenance practices.

With average freight-car axle loads steadily increasing over time, a question arises: what is the minimum rail size needed to maintain structural integrity under heavy axle loads? This paper describes the engineering analyses used to develop the technical information, which in turn is used to make rational judgments to answer this question. These engineering analyses were developed during the course of long-term research sponsored by the FRA Office of Research and Development and conducted by the Volpe National Transportation Systems Center.

\section{FRAMEWORK FOR ESTIMATING TRACK CAPACITY}

A general framework to evaluate the structural limitations of track to train-induced loads was introduced in previous paper [3]. The framework is presented in the form of a flow diagram in Figure 3. Operational factors are shown in this framework to determine the magnitude of the applied wheel loads. These operational factors include the characteristics of different car types, such as vehicle weight and axle spacing, in combination with train speed and track condition (i.e. alignment, profile, cross-level, and gage). In principle, speed and track condition are separate factors. In practice, however, the two are related: higher maximum operating speeds for freight and passenger traffic are allowed in the regulations as the track classification becomes higher. Improved track conditions are implied as the track classification becomes higher. Structural factors are shown in the framework to comprise the rail and the support conditions (i.e. foundation and ties). The response of the track structure to the applied wheel loads is then calculated in terms of rail stresses. To evaluate the load-bearing capacity of rail, a criterion is assumed to define a condition which represents failure of the rail. For example, failure might be considered as excessive bending that caused permanent deformations or high stresses. Another fatigue mode to consider might be the development of fatigue cracks in the rail head due to repetitive wheel loads. Crack initiation life and crack propagation life (also referred to as slow crack-growth life) of rails are important considerations for safe operations.

In this paper, the following criteria are used to conduct track capacity evaluations in terms of rail structural integrity: (1) rail deflections and bending stresses, and (2) metal fatigue.

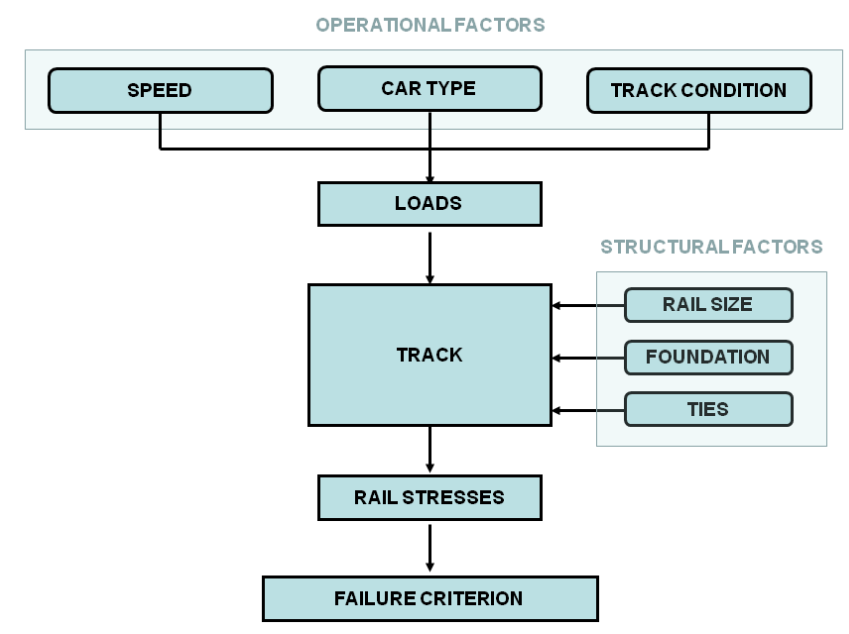

Figure 4: Flow Diagram for Estimating Track Capacity Limits 


\section{RAIL DEFLECTIONS AND BENDING STRESSES}

The American Railway Engineering and Maintenance-ofway Association (AREMA) Manual [4] recommends that the vertical rail deflection should not exceed 0.25 inch and that rail stress due to flexure should not exceed $25 \mathrm{ksi}$ for continuous welded rail (CWR). The stress limit is derived from assuming allowances to account for various effects in addition to vertical load. The derivation of this stress limit recognizes that vertical load is not the only factor contributing to the level of stress, but it is assumed to be the dominant factor. Table 1 lists the values of the allowances from the AREMA manual, which may be considered as compensating factors used to adjust the vertical bending stress. The purpose of establishing permissible limits is to ensure that repetitive rail deflection does not excessively disturb the ballast and cause accelerated line and surface deterioration.

Table 1: AREMA Acceptable Rail Stress for CWR

\begin{tabular}{lc}
\hline Reduction Factor & Allowance \\
\hline Lateral Bending & $20 \%$ \\
Track Condition & $25 \%$ \\
Rail Wear and Corrosion & $15 \%$ \\
Unbalanced Superelevation & $15 \%$ \\
Temperature Stress & $7,000 \mathrm{psi}$ \\
Rail Yield Strength & $70,000 \mathrm{psi}$ \\
\hline
\end{tabular}

In this paper, vertical rail deflections and bending stresses are calculated using the theory of beams on elastic foundation [5]. Furthermore rail deflections and stresses are calculated assuming the axle loading configuration shown in Figure 5. In this figure, the static wheel load, denoted as $V$, is the same for both wheels and the axle spacing, denoted as $a$, is equal to 70 inches.

For the axle loading configuration shown in Figure 5, vertical deflection along the rail in the longitudinal direction, $x$ is:

$\delta(x)=\frac{V \lambda_{V}}{2 k_{V}} f_{1}(x)$

where

$\lambda_{V}=\sqrt[4]{\frac{k_{V}}{4 E I_{y y}}}$

and

$f_{1}(x)=e^{-\lambda_{v}\left|x+\frac{a}{2}\right|}\left[\cos \lambda_{V}(x+a / 2)+\sin \lambda_{V}|x+a / 2|\right]$

$+e^{-\lambda_{V}\left|x-\frac{a}{2}\right|}\left[\cos \lambda_{V}(x-a / 2)+\sin \lambda_{V}|x-a / 2|\right]$
In these equations, $k$ is the foundation modulus (in psi), $E$ is the modulus of elasticity for rail steel $\left(30 \times 10^{6} \mathrm{psi}\right.$ assumed), and $I_{y y}$ is the area moment inertia of the rail for vertical bending (in inch $^{4}$ ). The corresponding bending moment along the rail for the assumed loading configuration is:

$M(x)=\frac{V}{4 \lambda_{V}} f_{2}(x)$

where

$$
\begin{aligned}
& f_{2}(x)=e^{-\lambda_{V}\left|x+\frac{a}{2}\right|}\left[\cos \lambda_{V}(x+a / 2)-\sin \lambda_{V}|x+a / 2|\right] \\
& +e^{-\lambda_{V}\left|x-\frac{a}{2}\right|}\left[\cos \lambda_{V}(x-a / 2)-\sin \lambda_{V}|x-a / 2|\right]
\end{aligned}
$$

The maximum bending stress occurs at the field side of the rail base, and is calculated from:

$$
\sigma(x)=\frac{M(x) h_{c}}{I_{y y}}
$$

where $h_{C}$ is the distance from the base of the rail to the neutral axis.

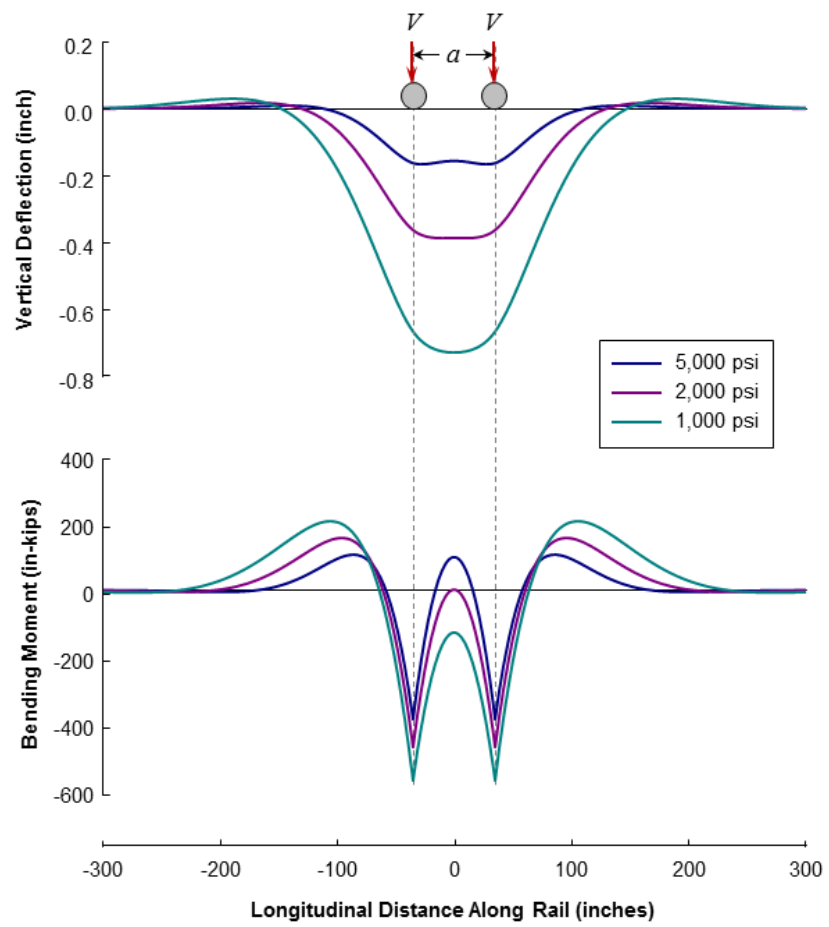

Figure 5: Vertical Rail Deflections and Bending Moments for 115 RE on FRA Class 3 Due to 39-ton Axle Loading 
Table 2 lists section properties for four rail sizes, which are studied in this paper for deflections and bending stresses.

Table 2: Rail Section Properties

\begin{tabular}{lcc}
\hline Rail size & $\begin{array}{c}I_{y y} \\
\left(\text { in }^{4}\right)\end{array}$ & $\begin{array}{c}h_{c} \\
\text { (inches) }\end{array}$ \\
\hline 85 ASCE & 30.1 & 2.47 \\
100 RE & 49.0 & 2.75 \\
115 RE & 65.6 & 2.98 \\
132 RE & 88.2 & 3.2 \\
\hline
\end{tabular}

Because of track irregularities and wheel flats, dynamic wheel loads may be higher than the static value. The dynamic effect is considered by multiplying the static wheel load by a load amplification or speed factor. The AREMA Manual [4] recommends using the following formula for speed factor:

$$
D L F=1+\frac{33 v}{100 D_{w}}
$$

where $D L F$ is the dynamic load factor, $v$ is the train speed (in miles per hour), and $D_{W}$ is the wheel diameter (in inches). In this paper, a wheel diameter of 36 inches is assumed. This factor does not include the effect of variations in track geometry or vehicle type. Moreover, the AREMA speed factor is used as a multiplying factor on the deflection and bending stress to account for dynamic effects. The train speed in equation (7) is based on the maximum freight speeds specified in the FRA Track Safety Standards, which are published in the Code of Federal Regulations, Title 49 \$213.9 [6]. The maximum freight train speeds depend on the FRA track class, and are summarized in Table 3 for Classes 3 through 5. Current federal standards require annual testing (i.e. inspection for defects) of all rail on which freight trains operate at more than $40 \mathrm{mph}$.

Table 3: FRA Track Class and Maximum Operating Speeds

\begin{tabular}{cc}
\hline $\begin{array}{c}\text { FRA Track } \\
\text { Class }\end{array}$ & $\begin{array}{c}\text { Maximum Freight } \\
\text { Train Speed } \\
(\mathrm{mph})\end{array}$ \\
\hline 3 & 40 \\
4 & 60 \\
5 & 80 \\
\hline
\end{tabular}

Figure 5 shows vertical rail deflection distributions for 115 RE rail on FRA Class 3 track for different values of foundation modulus due to the axle loading in which the static load for each wheel is 39 kips. From Table 3, the maximum freight train speed for FRA Class 3 is $40 \mathrm{mph}$. Obviously the stiffer foundation modulus results in smaller deflection. The figure also shows that the longitudinal location of the maximum deflection depends on the foundation modulus. For a foundation modulus of $1,000 \mathrm{psi}$, the maximum deflection of 0.729 inch occurs exactly at the midway point between the two wheels. For a foundation modulus of 5,000 psi, the maximum vertical deflection of 0.161 inch occurs at two locations between the two wheels. Interestingly when the foundation modulus is equal to $2,000 \mathrm{psi}$, the maximum deflection appears to occur over a span of several inches. These results indicate that a 39-ton axle load causes rail deflections that exceed the allowable deflection of 0.25 inch if the foundation modulus is 1,000 and 2,000 psi. On the other hand, axle loads greater than 39-tons would be permissible if the foundation modulus is 5,000 psi.

Figure 5 also shows the bending moment distributions for 115 RE rail on FRA Class 3 track subjected to same axle loading with varying foundation modulus. The figure indicates that the bending moment, and therefore the corresponding bending stress, decreases with increasing foundation support. In addition, the figure clearly shows that the maximum bending moment occurs directly beneath the wheels.

The beam on elastic foundation analysis can be manipulated to derive an expression to determine the static wheel load that would cause the maximum rail deflection to reach the permissible limit:

$$
V_{\max }=\frac{1}{D L F} \cdot \frac{2 k_{V} \delta_{\text {allow }}}{\lambda_{V} f_{1}\left(x_{1}\right)}
$$

where $\delta_{\text {allow }}$ is the allowable or permissible rail deflection $(0.25$ inch) and $x_{1}$ is the location at which the maximum deflection occurs. Moreover, $x_{l}$ is determined by taking the derivative of equation (2) with respect to $x$, setting the derivative equal to zero, and finding the root of the resulting equation. The procedure for determining $x_{l}$ is carried out numerically.

In this paper, rail capacity is defined as the maximum static wheel load that satisfies both criteria, i.e. the 0.25 -inch deflection limit and the 25-ksi bending stress limit. Therefore, the rail capacity is calculated as the lower of the two results from applying equations (8) and (9). Such results are compared over a range of foundation modulus between 1,000 and 10,000 psi in Figure 6 for 115 RE rail on FRA Class 5, corresponding to a maximum freight train speed of $80 \mathrm{mph}$. The values for foundation modulus are representative of varying degrees of track support ranging between poor and excellent conditions. The curves for the deflection limit and for the bending limit intersect at a foundation modulus of 4,590 psi and a maximum static wheel load of 43.1 kips. Therefore the maximum static wheel load is controlled by the permissible deflection for foundation moduli less than 4,590 psi. For foundation moduli greater than $4,590 \mathrm{psi}$, the maximum static wheel load is controlled by the permissible bending stress. These results may also be interpreted as indicating the minimum foundation modulus required to support the rail under a given static wheel load in order to satisfy the deflection and bending stress criteria. For instance, a foundation modulus of at least $4,110 \mathrm{psi}$ is needed to ensure that the maximum deflection and the maximum bending stress caused by 39 -ton axle loads are less than their respective allowable limits. 


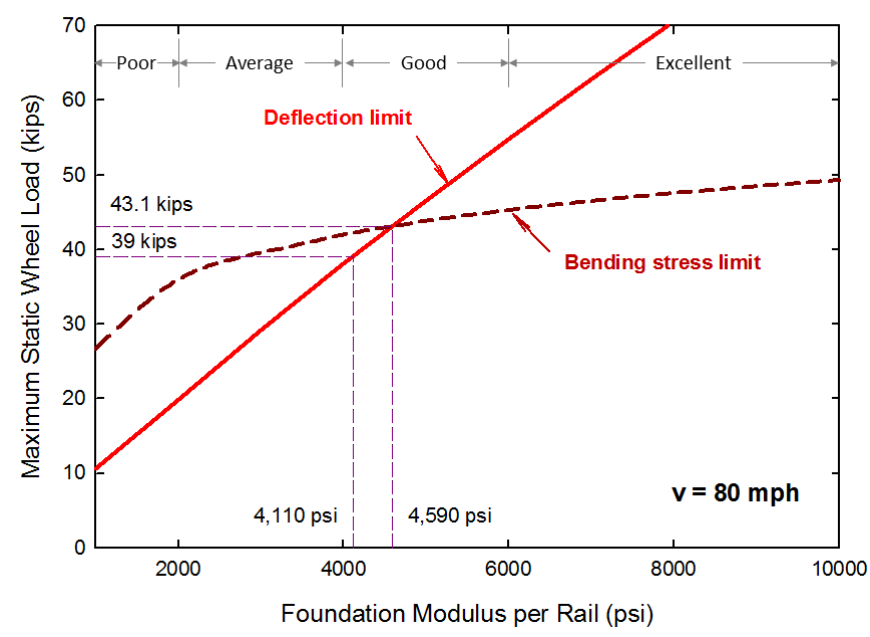

Figure 6: Rail Capacity Curves for 115 RE on FRA Class 5 Based on Conventional Stress Analysis

The conventional analysis is applied to calculate rail capacity curves for four different rail sizes FRA Track Classes 3 through 5. The foundation modulus required for a given rail size to support a 39-ton axle load traveling at the maximum allowable freight speed for the assumed FRA track class is then estimated from each of the rail capacity curves is shown in Figure 7. In this figure, the foundation modulus needed to support 85 ASCE rail on FRA Track Classes 4 and 5 is actually much greater than $10,000 \mathrm{psi}$, which is a value usually associated with concrete tie track. Moreover, the values of foundation modulus shown in the figure are generally representative of track support conditions that are considered to be above average.

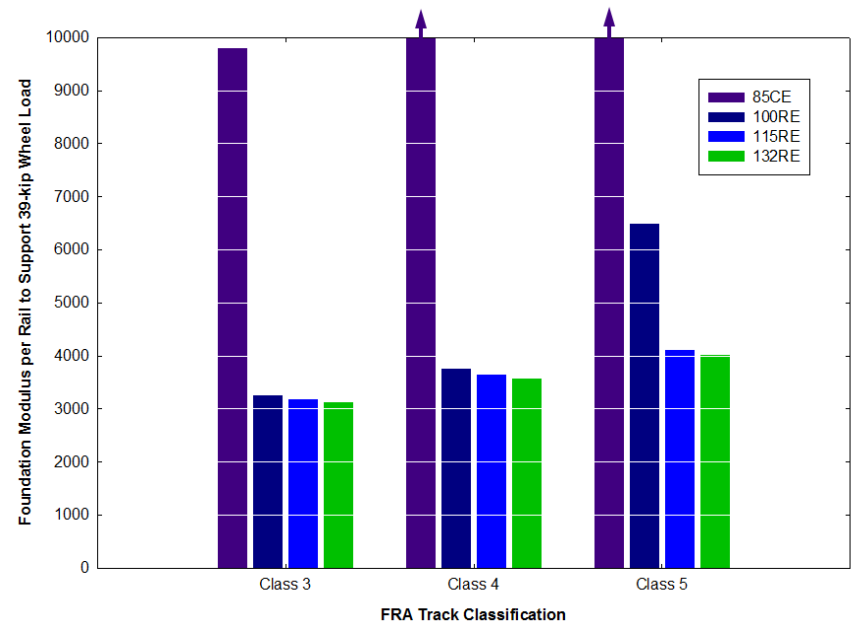

Figure 7: Foundation Moduli Required to Support Various Rail Sizes on Different FRA Track Classes Based on Conventional Analysis
In the conventional analysis method, compensating factors are applied to the vertical bending stress to account for other effects such as lateral bending and thermal stress. However, bending stresses are also calculated in this paper using an alternate method in which lateral and torsional flexure of the rail are coupled through an analysis of the lateral displacements and rotation of the rail about the shear center. This beam theory formulation, which was originally developed by Timoshenko and Langer [7], considers equilibrium of an idealized rail supported by linear elastic springs in the vertical, lateral, and torsional directions, as shown in Figure 8.

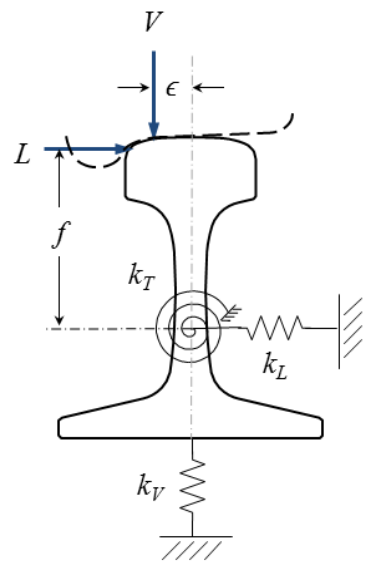

Figure 8: Rail Cross Section for Timoshenko and Langer Analysis

In the Timoshenko and Langer analysis, the bending stress of the rail is calculated as the sum of three components corresponding to vertical, lateral, and torsional loads applied to the rail (Figure 9). Moreover, the combined influence of vertical and lateral loads, which also produce a twisting moment, are taken into account in the analysis explicitly. Details of the Timoshenko and Langer analysis, as applied to the determine rail capacity, are given in the appendix.
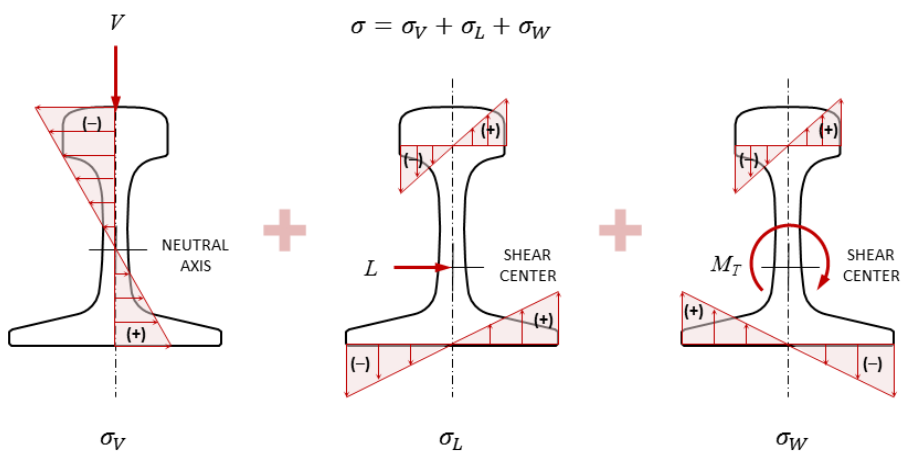

Figure 9: Superposition of Bending Stress Components 
Figure 10 shows results from applying the Timoshenko and Langer stress analysis to calculate the rail capacity for $115 \mathrm{RE}$ on FRA Class 5. The curve corresponding to the 0.25 -inch deflection limit is unaltered compared to Figure 6, but the curve associated with the stress limit has shifted downward compared to the bending-limit curve based on using the conventional stress analysis. That is, the alternate stress analysis method provides a more conservative estimate of the maximum static wheel load than the conventional method. Consequently the maximum static wheel load is controlled by the deflection limit for foundation moduli less than 3,640 psi, compared to 4,590 psi in the previous result. Figure 10 indicates that the maximum axle load capacity of 39 tons is controlled by the bending stress limit. The results from the conventional method, shown in Figure 6, show that the 39-ton axle load capacity is controlled by the deflection. Moreover, the Timoshenko and Langer stress analysis indicates that the minimum foundation modulus needed to support 39-ton axle loads is $9,110 \mathrm{psi}$, compared to $4,110 \mathrm{psi}$ based on the conventional analysis. The difference in track support condition represents a shift from above average to excellent.

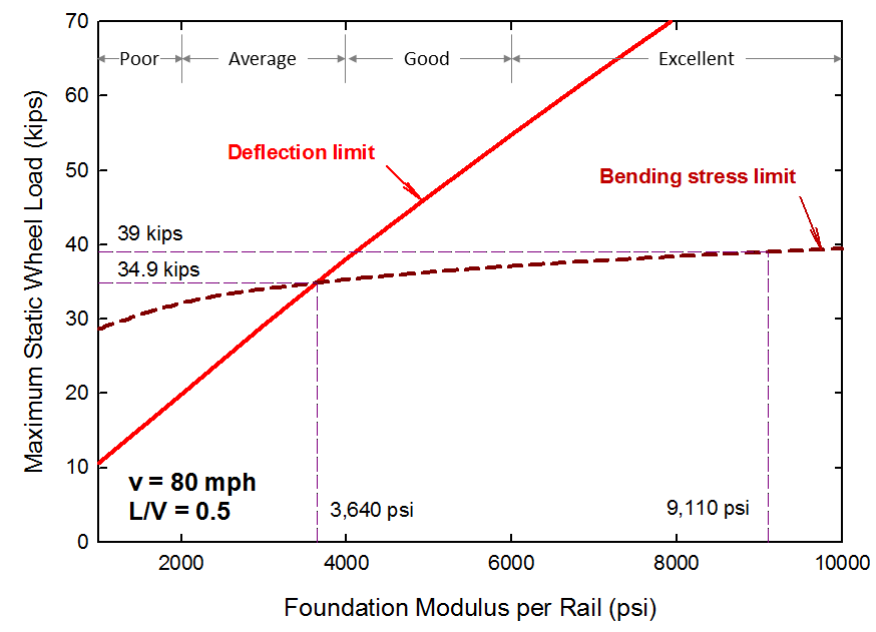

Figure 10: Rail Capacity Curves for 115 RE on FRA Class 5 Based on Timoshenko and Langer Stress Analysis

Rail capacity calculations are repeated using the Timoshenko and Langer stress analysis for the same combinations of rail sizes and FRA track classes as shown previously. In the alternate stress analysis, lateral load is explicitly taken into account. Moreover, a value of lateral-tovertical $(L / V)$ load ratio of 0.5 is assumed. Steady-state $L / V$ ratios are generally associated with wheel/rail loading on curved track. However, truck hunting and engagements with track alignment and/or gage irregularities can generate dynamic $L / V$ ratios well above steady-state. Results from the Timoshenko and Langer analysis are shown in Figure 11 for the foundation modulus required to support various rail sections subjected to the 39-ton axle loading on the three different FRA track classes.
The foundation moduli estimated from the Timoshenko and Langer analysis are generally higher than those estimated using the conventional analysis method.

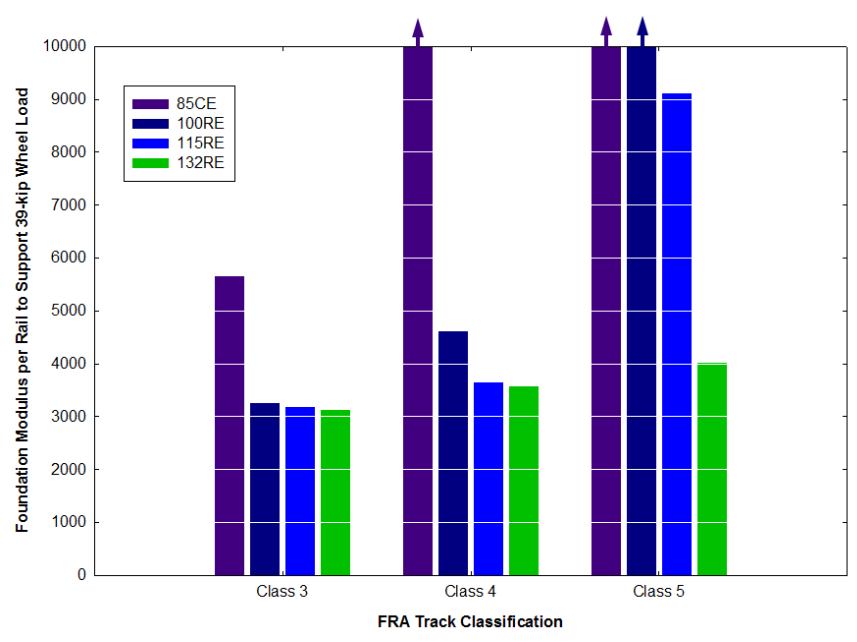

Figure 11: Foundation Moduli Required to Support Various Rail Sizes on Different FRA Track Classes Based on Timoshenko and Langer Analysis

The largest differences between these two methods are evident in the results for FRA Class 5 track. Moreover, the Timoshenko and Langer stress analysis method provides more conservative estimates for track support conditions needed to support heavy wheel/axle loads than the conventional analysis method. In those cases where the conservatism is present, the foundation modulus needed to support the rail under axle loading is controlled by the maximum stress limit. The stress limit, however, addresses only a single excursion of the assumed axle loading configuration. Multiple excursions or the repetition of the same axle load, i.e. fatigue loading, have other consequences, which are examined as follows.

\section{METAL FATIGUE}

Fatigue life of rail comprises two stages: initiation life and propagation life. Engineering models have been developed over the course of performing previous research to calculate fatigue crack initiation life (also referred to as shell nucleation life) and propagation life (also referred to as slow crack growth life). The schematic in Figure 12 describes three regions corresponding to a relatively long initiation stage, a transition stage which is hard to define, and a propagation stage. The vagueness of the transition stage stems from uncertainty in crack detection. In addition, data characterizing the initiation stage typically has large variability. The most repeatable data for fatigue life has been generated and analyzed in the propagation stage. Therefore, a conservative approach is taken this paper to examine the effects of metal fatigue by assuming the existence of an initial flaw and analyzing the fatigue crack growth behavior of rail in terms of propagation life. 


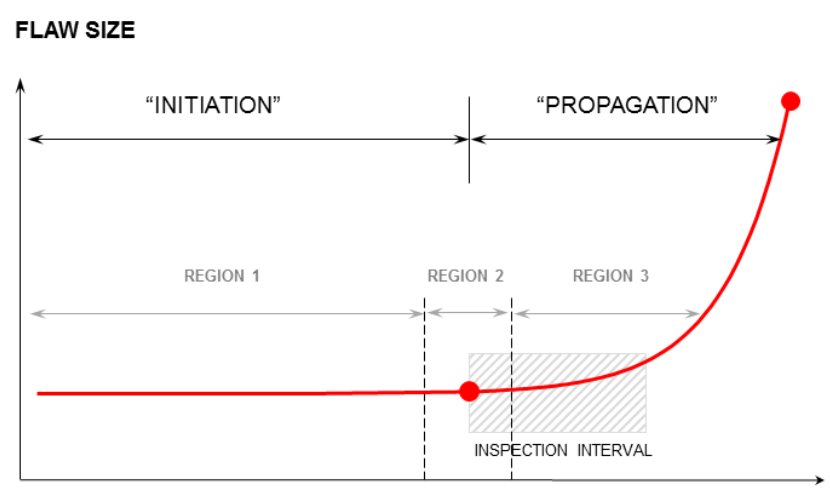

LOAD CYCLES OR TONNAGE

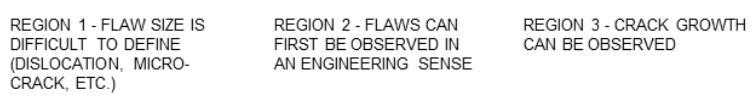

Figure 12: Schematic Relations between Shell Nucleation Life and Propagation Life of Rail

\section{Shell Nucleation Life}

Longitudinal fatigue cracks known as shells develop in the heads of railroad rails due to plastic deformation caused by the repeated action of wheel loads. Shells occur in the vicinity of the gage corner of the rail head, oriented roughly parallel to the running surface. The shell can either protrude to the running surface and create a spall, or turn downward to create a transverse defect known as a detail fracture. The latter scenario is shown schematically in Figure 13. Shells represent the initial stage of fatigue crack growth and are, therefore, associated with the initiation of fatigue cracks. Moreover, a shell in the rail head is not considered as a direct threat to rail structural integrity because its orientation is horizontal or parallel to the running surface. But once a detail fracture forms, rail integrity is threatened because a detail fracture is oriented in the transverse direction, which is perpendicular to the running surface. A defect of sufficient size growing in the transverse plane could cause fracture of the rail. Furthermore, the relative population of shells is large compared to the population of detail fractures because not all shells turn downward.

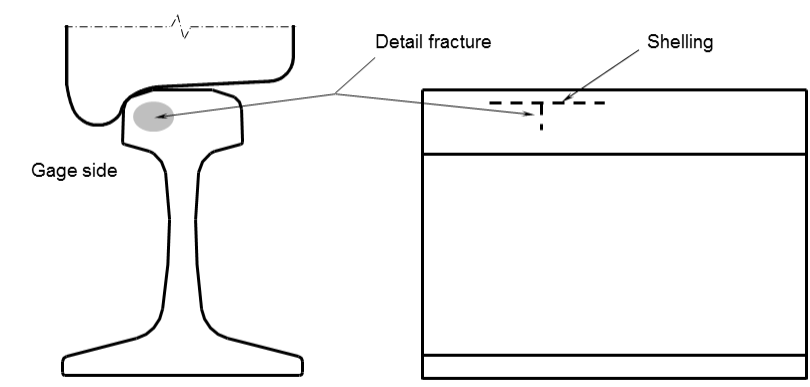

Figure 13: Relative Positions of Shelling and Detail Fractures in Rail
The tendency for shells to grow out-of-plane to form a detail fracture is related to the local state of stress caused by mixed-mode loading, and has been studied previously $[8,9]$. The factors affecting the transition from shelling to detail fractures include residual stress, shell depth, shell length, and coefficient of friction at the wheel/rail contact. The previous study found that greater tensile longitudinal residual stress increases the likelihood that the shell will turn downward. Conversely, increased tensile vertical residual stress was found to reduce the tendency for the shell to turn downward. The mechanics of the crack path trajectory are beyond the scope of this paper.

Gross field observations suggest that shell nucleation life exhibits significant scatter. The tonnage for shell nucleation can be in the range of 70 to 200 million gross tons (MGT) of accumulated traffic. These fatigue cracks generally appear at depths between 6 and 8 millimeters below the rail running surface. Mechanics-based models have been developed to predict shell nucleation life [10]. Results from these models exhibit qualitative agreement with field observations, but additional work is needed to verify and validate these predictive models.

\section{Propagation Life}

Propagation life of detail fractures represents the second stage of fatigue life as shown in Figure 14. Fracture mechanics principles have been applied over the course of previous research to develop an engineering model to study the propagation or growth behavior of detail fractures under varying operational, track, and environmental conditions. Specific details of the engineering model are described in Reference [11]. The model is used to calculate the slow crackgrowth life, which is defined as the accumulated tonnage to grow a detail fracture from a barely detectable size to a size that is large enough to cause rail failure under the next train passage. The schematic of slow crack growth life shown in Figure 14 is essentially the third region in Figure 12. Moreover, the term "slow crack growth" characterizes the potential opportunities to detect cracks before they grow to critical size.

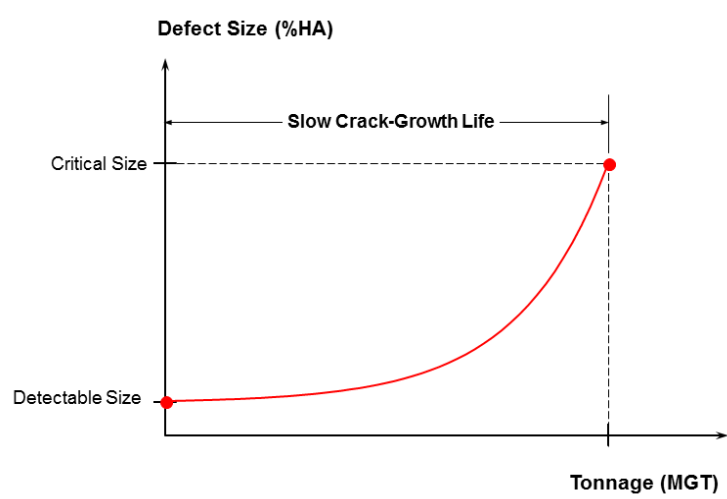

Figure 14: Schematic of Slow Crack Growth Life 
In this paper, the slow crack growth life is calculated as the tonnage to grow a detail fracture from 10 percent rail head area $(\% \mathrm{HA})$ to $80 \% \mathrm{HA}$. The assumption of $10 \% \mathrm{HA}$ is a reasonable estimate of the minimum detectable size. In addition, field experience suggests that rails in average service environments can survive with detail fractures of size up to 80 $\% \mathrm{HA}$.

Safety is maintained by inspecting frequently enough to ensure that transverse cracks such as detail fractures are discovered and removed before they grow large enough to cause rail failure. A reasonable interval between inspections would be a time or tonnage that is somewhat shorter than the expected growth life. Ideally inspection intervals equal to fractions of the expected growth life would afford more than one opportunity to find defects that might not have been detected in previous inspections before they grow to critical size. For example, an inspection interval equal to $1 / 2$ of the expected growth life might provide two chances to discover a crack before it reaches critical size. Moreover, the slow crackgrowth life defines the window of opportunity to detect cracks before they grow large enough to cause rail failure.

Figure 15 shows the results of the calculations for slow crack growth life as a function of the vertical bending inertia for several rail sizes. Rail sizes vary from 85 to $155 \mathrm{lb}$ per yard. In these results, the average wheel load is 39 kips while the foundation modulus is varied between 1,000 psi and 5,000 psi and. Linear regression curves are fit to the calculated results for the same foundation modulus. The figure illustrates the general trend that slow crack growth life becomes longer as rail size increases.

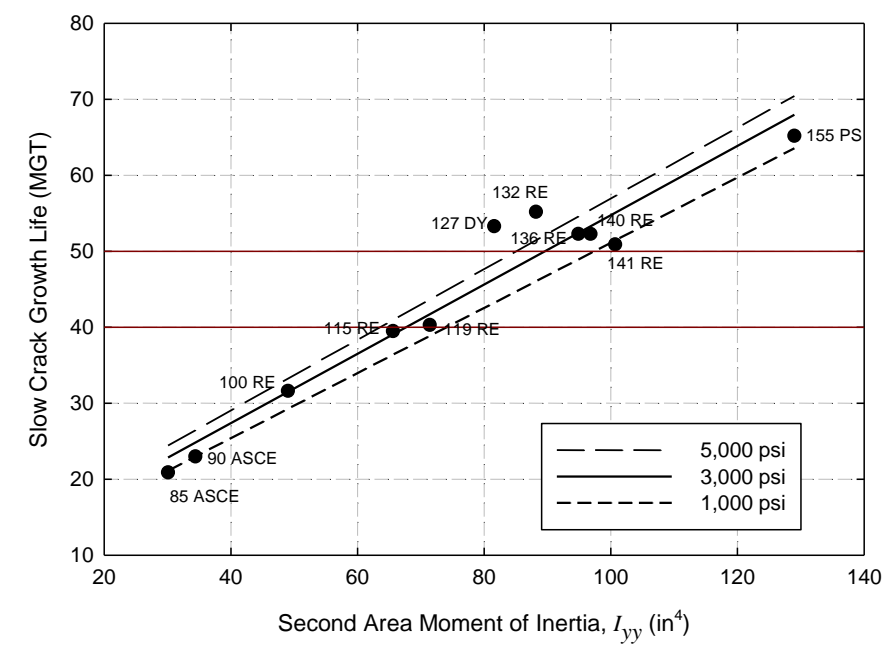

Figure 15: Slow Crack Growth Life as a Function of Bending Inertia and Varying Foundation Modulus (39-kip Average Wheel Load)

Assuming that average test intervals are between 20 and 25 MGT on medium tonnage lines [12] and that the fraction of expected life to establish these intervals is $1 / 2$, nominal propagation lives would be between 40 and 50 MGT. If a limit of 50 MGT is established as an upper bound limit on propagation life, then rail sizes $119 \mathrm{RE}$ and less would have slow crack growth lives below the upper bound. That is, the growth rate of such rails under heavy axle loads would be too rapid to find under nominal rail testing. If the upper bound is set equal to $40 \mathrm{MGT}$, the growth lives of defects in rail sizes $115 \mathrm{RE}$ and lower would be less than the upper bound limit.

Figure 16 presents results for slow crack growth life as a function of average wheel load for three different rail sizes: $100 \mathrm{RE}, 115 \mathrm{RE}$, and $132 \mathrm{RE}$. The range of average wheel loads varies between 9.9 and 38.5 kips. These results indicate two trends: propagation life becomes is shorter for lighter rails and propagation life is shorter for heavier wheel loads.

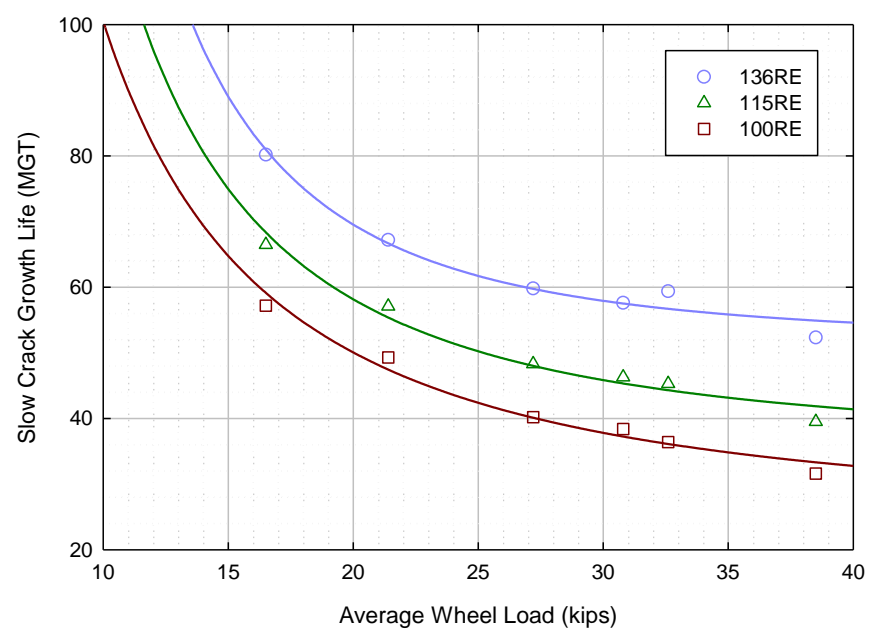

Figure 16: Effect of Average Wheel Load and Rail Size on Slow Crack Growth Life

\section{DISCUSSION}

A possible strategy to manage the operational transition from moderate to heavier axle/wheel loads might be to decrease the interval between inspections, thereby conducting rail tests more frequently to detect internal transverse defects before they grow to critical size. This strategy suggests that an equivalent level of safety can be achieved by inspecting rail subjected to heavy loads more frequently than rail subjected to lower loads. This concept of adjusting the inspection frequency based on average axle/wheel loads was examined in previous work using Monte Carlo methods [13]. The previous work demonstrated the concept in principle. The results presented in this paper provide a more quantitative assessment. For example, based on the results shown in Figure 22, the maximum interval between rail tests on track with $100 \mathrm{RE}$ rail subjected to average wheel loads of 39 kips should not be longer than 30 MGT. Ideally, the test interval in this case should be on the order of 15 MGT (one half of 30 MGT) in order to accommodate at least two rail tests within the growth life. 
The analyses used in this paper assume that the foundation is linear, elastic, and continuous. Modifications to these analyses can be made to account for the effects of discrete support such as missing ties (see e.g. [3]). In addition, effects such as rail head wear and residual stresses from head hardening have not been examined. Since the analyses presented in this paper are comparative, the qualitative trends of the results are not expected to change significantly if these factors and assumptions regarding the foundation modulus are taken into account. Future work may be conducted to address these factors more explicitly.

\section{CONCLUDING REMARKS}

This paper examines the demands placed on railroad track through the evolution of train operations to higher speeds and heavier wheel loads. Demand is considered through rail integrity, which in turn is studied in terms of two potential failure modes. The first mode is a combination of excessive rail vertical deflection and bending stress. The second mode is metal fatigue characterized in terms of propagation life or slow crack growth life, which is defined as the time or tonnage for a transverse defect such as a detail fracture to grow from barely detectable size to the size at which rail failure is expected to occur.

Rail deflections and bending stresses are examined for various combinations of rail sizes, foundation modulus, and FRA track class. Stresses are calculated using two different methods. A conventional method is used in which empirical or compensating factors are used to adjust the vertical bending stress for effects such as lateral load and temperature. An alternate method, based on a beam theory analysis developed by Timoshenko and Langer [7], is also used to account for the effect of lateral load and temperature in an explicit manner. Moreover, the Timoshenko and Langer analysis produces more conservative estimates for rail capacity than the conventional method.

Heavy wheel loads are assumed to be 39 kips and above. The minimum rail size to support heavy wheel loads while not exceeding permissible limits on deflection and bending stress are found to depend on FRA track class (implying a dependence on train speed) and foundation modulus. Both stress analysis methods indicate that the lightest rail size considered in this study, 85 ASCE, requires exceptionally high or stiff foundation moduli to support heavy loads on FRA Track Classes 3, 4 and 5. Based on the Timoshenko and Langer analysis, high foundation moduli may also be required for $100 \mathrm{RE}$ and $115 \mathrm{RE}$ on FRA Class 5.

In terms of fatigue propagation life or slow crack growth life, the minimum rail size to support heavy wheel loads depends on the inspection interval. A possible strategy to deal with heavier wheel loads is to conduct more frequent rail tests than those conducted on rail subjected to nominal wheel loads. For example, $115 \mathrm{RE}$ rail subjected to average axle loads of 39 kips may require rail testing at intervals of 10 to $15 \mathrm{MGT}$ in order to maintain an equivalent level of safety compared to the same rail under 33-kip average axle loads and testing intervals between 20 and 25 MGT.

\section{NOMENCLATURE}

$a \quad=$ Axle spacing (70 inches)

$A_{R} \quad=$ Cross sectional area of entire rail (in $\left.\mathrm{in}^{2}\right)$

$C \quad=$ Torsion constant (in $\mathrm{lb}_{\mathrm{b}} \mathrm{in}^{2}$ )

$D \quad=$ Warping constant $\left(\right.$ in $\left.\mathrm{lb}-\mathrm{in}^{2}\right)$

$D_{W} \quad=$ Wheel diameter (36 inches)

$E \quad=$ Modulus of elasticity of rail steel $\left(30 \times 10^{6} \mathrm{psi}\right)$

$f \quad=$ Distance from lateral load to shear center

$G \quad=$ Shear modulus (in psi)

$h=$ Distance between centroids of head and base

$h_{C} \quad=$ Distance from bottom of rail to centroid of rail

$h_{C H}=$ Distance from bottom of rail to centroid of rail head

$h_{C B}=$ Distance from bottom of rail to centroid of rail base

$h_{S} \quad=$ Distance from bottom of rail to shear center

$h_{\text {TOT }}=$ Total height of rail

$I_{y y} \quad=$ Vertical bending inertia for entire rail $\left(\right.$ in in $\left.^{4}\right)$

$I_{z z} \quad=$ Lateral bending inertia for entire rail $\left(\right.$ in in $\left.^{4}\right)$

$I_{z z B} \quad=$ Lateral bending for rail base only (in in ${ }^{4}$ )

$I_{z z H} \quad=$ Lateral bending for rail head only (in in ${ }^{4}$ )

$k_{L} \quad=$ Lateral foundation modulus per rail (in psi)

$k_{T} \quad=$ Torsional modulus per rail $\left(10^{5} \mathrm{lb}\right.$-in/rad-in $)$

$k_{V} \quad=$ Lateral foundation modulus per rail (in psi)

$L \quad=$ Lateral wheel load

$M_{T} \quad=$ Twisting moment about shear center

$S \quad=$ Total bending stress per unit load

$s_{L} \quad=$ Unit stress due to lateral flexure

$s_{V} \quad=$ Unit stress due to vertical flexure

$s_{W} \quad=$ Unit stress due to warping

$v \quad=$ Train speed in $\mathrm{mph}$

$V \quad=$ Vertical wheel load

$w_{B} \quad=$ Width of rail base

$w_{H} \quad=$ Width of rail head

$x=$ Longitudinal direction along rail

$\alpha=$ Wavelength parameter for warping (in $1 /$ in)

$\beta=$ Wavelength parameter for warping (in 1/in)

$\delta \quad=$ Vertical rail deflection

$\epsilon=$ Distance from vertical load to vertical centerline

$\gamma=$ Wavelength parameter for warping (in 1/in)

$\lambda_{L} \quad=$ Wavelength parameter for lateral flexure (in $1 /$ in)

$\lambda_{V} \quad=$ Wavelength parameter for vertical flexure (in 1/in)

$\sigma_{L} \quad=$ Lateral bending stress

$\sigma_{V} \quad=$ Vertical bending stress

$\sigma_{W} \quad=$ Warping stress

$v \quad=$ Poisson's ratio $(0.3)$

\section{ACKNOWLEDGMENTS}

The work described in this paper was carried out under the Rail Integrity Project in the Track Safety Research Program sponsored by the Office of Research and Development, Federal Railroad Administration, US Department of Transportation, under the direction of Mr. Gary Carr, Chief of the Track 
Research Division. Mr. Leith Al-Nazer is the Project Manager for the research related to rail integrity.

The authors also wish to acknowledge Ms. Michelle Muhlanger who performed preliminary calculations for this paper.

\section{REFERENCES}

1. Railroad Facts, 2012 edition, Association of American Railroads, Washington, D.C., November 2012.

2. Federal Railroad Administration, Railroad Accident and Incident Report System (RAIRS) http://safetydata.fra.dot.gov/OfficeofSafety/Default.aspx

3. Jeong, D.Y., Perlman, A.B., "Estimating Track Capacity Based on Rail Stresses and Metal Fatigue," Proceedings of the 2011 ASME Rail Transportation Division Fall Technical Conference, RTDF2011-67001, September 2011.

4. AREMA Manual for Railway Engineering, Volume 4: Systems Management, Chapter 16: Economics of Railway engineering and Operations, American Railway Engineering and Maintenance-of-Way Association (1999).

5. Hetenyi, H., Beams on Elastic Foundation, University of Michigan Press, Ann Arbor, MI (1974).

6. Code of Federal Regulations, Title 49 - Transportation, Part 213 - Track Safety Standards, Section 213.109 Crossties, Federal Railroad Administration, October 2009.

7. Timoshenko, S., Langer, B.F., "Stresses in Railroad Track," ASME Transactions 54, 277-293 (1932).

8. Farris, T.N., Keer, L.M., Steele, R.K., "The effect of service loading on shell growth in rails," Journal of Mechanics and Physics of Solids 35, 677-700 (1987).

9. Steele, R.K., "Recent North American experience with shelling in railroad rails," Report No, R-699, AAR Chicago Technical Center, Chicago, IL, September 1988.

10. Jeong, D.Y., Orringer, O., Perlman, A.B., Rice, R.C., "Beam theory predictions of shell nucleation life." Contact Mechanics and Wear of Rail/Wheel Systems II (G.M.L. Gladwell, H. Ghonem, and J. Kalousek, ed.), University of Waterloo Press, addendum (1987).

11. Orringer, O., Tang, Y.H., Gordon, J.E., Jeong, D.Y., Morris, J.M., Perlman, A.B., "Crack Propagation Life of Detail Fractures in Rails," Volpe Center Final Report DOT/FRA/ORD-88/13, October 1988.

12. Orringer, O., "Control of Rail Integrity by Self-adaptive Scheduling of Rail Tests," Volpe Center Final Report DOT/FRA/ORD-90/05, June 1990.

13. Jeong, D.Y., Gordon, J.E., "Evaluation of Rail Test Frequencies using Risk Analysis," Proceedings of the 2009 ASME Joint Rail Conference, JRC2009-63009, March 2009.

\section{APPENDIX - TIMOSHENKO AND LANGER ANALYSIS}

This appendix lists the equations used to calculate the maximum static wheel load based on the allowable stress calculated from using the Timoshenko and Langer analysis:
$V_{\max }=\frac{1}{D L F} \cdot \frac{\sigma_{\text {allow }}}{S}$

where $\sigma_{\text {allow }}$ is the allowable stress and $S$ is referred to as the unit stress (i.e. stress per unit load). The allowable stress is equal to the yield strength of rail steel (assumed to be $70 \mathrm{ksi}$ ) minus a nominal value for thermal stress (assumed to be $7 \mathrm{ksi}$ ), or $63 \mathrm{ksi}$. The unit stress consists of three components corresponding to vertical bending, lateral bending, and warping of the rail:

$S=s_{V}+s_{L}+s_{W}$

Moreover, $S$ is a function of the vertical load, $V$ and the lateralto-vertical load ratio, $L / V$. The unit stress due to vertical bending is:

$s_{V}=\frac{1}{4 \lambda_{V} \cdot \frac{h_{C}}{I_{y y}}}\left[1+e^{-\lambda_{v} a}\left(\cos \lambda_{V} a-\sin \lambda_{V} a\right)\right]$
$\lambda_{V}=\sqrt[4]{\frac{k_{V}}{4 E I_{y y}}}$

The unit stress due to lateral bending is:

$$
\begin{aligned}
& s_{L}=\frac{-L / V}{8 \lambda_{L}} \cdot \frac{w_{B}}{I_{z z}}\left[1+e^{-\lambda_{L} a}\left(\cos \lambda_{L} a-\sin \lambda_{L} a\right)\right] \\
& \lambda_{L}=\sqrt[4]{\frac{k_{L}}{4 E I_{z z}}}
\end{aligned}
$$

where the lateral foundation modulus is defined as $k_{L}=0.85 k_{V}$. The unit stress due to warping or torsion of the rail is:

$$
s_{W}=-\frac{(L / V) f-\varepsilon}{8 I_{z z H} h \alpha \beta} w_{B}\left[e^{-\alpha a}(\alpha \sinh \beta a-\cosh \beta a)-\beta\right]
$$

where

$$
\begin{aligned}
f & =h_{\text {TOT }}-h_{S} \\
\alpha & =\sqrt{\frac{C}{4 D h^{2}}+\gamma^{2}} \quad \beta=\sqrt{\frac{C}{4 D h^{2}}-\gamma^{2}} \quad \gamma=\sqrt[4]{\frac{k_{t}}{4 D h^{2}}} \\
C & =\frac{G A_{R}^{4}}{40\left[I_{y y}+I_{z z}+A_{R}\left(h_{C}-h_{S}\right)^{2}\right]} \\
D & =E \frac{I_{z z H} I_{z z B}}{I_{z z H}+I_{z z B}} \\
h & =h_{C H}-h_{C B} \\
G & =\frac{E}{2(1+v)}
\end{aligned}
$$

The variables in these equations are defined in the Nomenclature section. 